\title{
A SIMPLE METEOROLOGICAL PREPROCESSOR (SIMETPRO) FOR OPTIMIZING HANDS-ON APPLICATION OF AIR POLLUTION DISPERSION MODELS IN LIMITED DATA SCENARIOS
}

\author{
$*^{1}$ Abiye, O. E., ${ }^{2}$ Ajao, A. I., ${ }^{1}$ Borisade, A. O., ${ }^{2,3}$ Akinola, O. E., ${ }^{2}$ Sunmonu, L. A. and \\ ${ }^{2}$ Ayoola, M. A. \\ ${ }^{1}$ Centre for Energy Research and Development, Obafemi Awolowo University, Ile-Ife, Nigeria \\ ${ }^{2}$ Department of Physics and Engineering Physics, Obafemi Awolowo University, Ile-Ife, Nigeria \\ ${ }^{3}$ Key Laboratory for Aerosol-Cloud-Precipitation of China Meteorological Administration, Nanjing University of \\ Information Science and Technology, Nanjing, China \\ Correspondence: waleabiye@gmail.com or eabiye@cerd.gov.ng Mobile: +2348030507076 \\ (Received: $18^{\text {th }}$ March, 2019; Accepted: 10 $0^{\text {th }}$ June, 2019)
}

\section{ABSTRACT}

\begin{abstract}
This study presents preliminary test case of a Simple Meteorological Preprocessor (SIMETPRO) that is coupled from boundary layer scaling relationships for estimating deterministic surface layer parameters. The SIMETPRO is intended for teaching hands-on basics of meteorological preprocessing in limited data scenarios of West African sub-region and its subsequent application in air pollution dispersion models. A two-year dataset of routine meteorological parameters obtained from near-surface gradient measurement around a characteristic scrap-iron smelting industry in Ile-Ife, southern West Africa was used to test run the preprocessor. An independent field experiment of Eddy Covariance (EC) system complimented with profile measurement of air temperature, relative humidity and wind speed was used to validate sensible heat flux and friction velocity estimates from the SIMETPRO. Diurnal trend of the SIMETPRO outputs were realistic in representing diurnal changes of atmospheric dynamics. Time variation analyses of daytime (07:00-18:00 GMT+1) minimummaximum values were; friction velocity (FRV) $0.05-0.65 \mathrm{~ms}^{-1}$, mixing height $(\mathrm{MH}), \quad 200-3100 \mathrm{~m}$, sensible heat flux (SHF) $25-135 \mathrm{Wm}^{-2}$, potential temperature gradient $(\mathrm{PTG})-0.4-(-0.01)^{\circ} \mathrm{C} / \mathrm{m}$, convective velocity (COV) $0.2-1.5 \mathrm{~ms}^{-1}$. Nighttime (19:00 - 06:00 GMT+1) values were less variant with MH mostly below 500m, VPG between $0-0.6{ }^{\circ} \mathrm{C} / \mathrm{m}$ and SHF below $5 \mathrm{Wm}^{-2}$. Inter-annual trend level shows varied degree of values between seasons and years, mostly with peak values occurring in dry seasons. Preliminary limitations of the SIMETPRO validation were highlighted and future refinement direction pointed out. In summary, a handy meteorological tool for stepwise understanding of basic parameters required for running dispersion models was proposed and tested. Though further refinement is required, the SIMETPRO is nonetheless efficient in delivering the targeted objective.
\end{abstract}

Keywords: meteorology; preprocessor; air pollution; dispersion models; surface layer parameters

\section{INTRODUCTION}

Estimating air pollutants' emissions and their atmospheric dispersion from natural and anthropogenic sources has become a global demand to compliment limited in-situ measurement required for regulatory, compliance and environmental protection purposes especially in developing countries. Reliable ambient air pollutants estimates are therefore derived from well-formulated and tested regulatory air pollution models. To execute such models, deterministic surface layer parameters which describe the dynamical state of the atmospheric boundary layer are required as input. These parameters include the mean wind speed, ambient air temperature, boundary layer height, Bowen ratio, sensible heat flux, friction and convective velocity, atmospheric stability parameters, Moninobukhov's length, mechanical and convective mixing heights among others (Perry et al., 2003). However, not all of these parameters are routinely measured at meteorological stations due to spatiotemporal constraints in deploying equipment, technical capability and manpower. The need therefore arises to estimate the surface layer parameters in terms of routinely measured meteorological variables using well tested and validated parametric relationship through meteorological preprocessing (Jegede, 1994a). A number of meteorological preprocessors have been developed and well tested (Perry. 1992; Hanna and Chang, 1993, Karppinen et al., 1997; Cimorelli et al., 2004), but none was experimented 
in Africa. As a result, they do not fully represent the conditions in tropical locations (Jegede, 1994a). This is mainly because many of the empirical parameters used in developing the preprocessors were obtained using boundary layer measurements from the mid-latitudes which is quite different from the conditions at lowlatitudes (Jegede, 1994b). In addition, the available preprocessors require input of upper air data which is not readily available for tropical locations and when available, they are often not on a sufficient timescale and the accessibility might be limited. As a result, the output parameters from these preprocessors do not accurately describe the atmospheric dynamics at the site of application. It is of great need therefore to provide alternative route to obtaining fairly reliable estimates of important atmospheric parameters for executing regulatory dispersion models at a tropical locations of Africa for instance. Hence, this study presents the architecture for a simple meteorological preprocessor for optimizing the use of air quality dispersion models for teaching atmospheric Physics/Science students and the appreciation of hands-on application in Nigeria. The aim of this study is not to discuss the dynamics of the parameters but rather to show the feasibility of the SIMETPRO output as an input for dispersion models. Depending on the dispersion model of choice, users who intend to apply SIMETPRO may have to convert the outputs into readable formats.

\section{MATERIALS AND METHODS Meteorological Measurement}

Quality-assured and high time resolution meteorological dataset (ambient air temperature, relative humidity, wind speed and direction, sensible and soil heat flux, net and global radiation) acquired in March - December, 2013 and January - June 2014 was utilized in this study. The dataset were products of a site specific measurement conducted in the vicinity of a scrapiron smelting factory in Fashina, Ile-Ife to model the dispersion of pollutants emission from the factory. Detailed description of the metrological mast installation, height configuration, meteorological parameters and corresponding sensors used, data archiving and post qualityassurance procedure has been given by Abiye et al., (2017).

\section{Parametric Models}

The following sub-sections describe the parametric models employed in estimating the surface layer characteristics at the study site.

\section{Lapse Rate $\left(\Gamma_{\mathrm{a}}\right)$ and Potential Temperature Gradient $\left(\Gamma_{\mathrm{d}}\right)$}

From the logarithmic finite difference approximation method (Arya, 2001), the gradients of ambient air temperature and potential temperature were estimated as follows

$\Gamma_{a}=\frac{\partial T}{\partial z} \cong \frac{1}{z_{m}} \frac{\Delta T}{\ln \left(z_{2} / z_{1}\right)}$

$\Gamma_{d}=\frac{\partial \Theta}{\partial z} \cong \frac{\partial T}{\partial z}+\Gamma$

$z_{1}$ and $z_{2}$ are the heights for the two levels of wind speed measured from the ground surface. $z_{\mathrm{m}}$ is the geometric mean height of the two levels. $\Gamma$ is the dry adiabatic lapse rate, approximately $-10{ }^{\circ} \mathrm{C} / \mathrm{km}$ or $0.01{ }^{\circ} \mathrm{C} / \mathrm{m}$ (Beychok, 2005).

\section{Richardson Number $\left(R_{i}\right)$ and Monin- Obukhov's (M-O) Stability Parameter ( $(\zeta)$}

The dimensionless dynamic stability parameter (Richardson number, $\left(R_{i}\right)$, was used as a measure of the intensity of turbulent mixing and also as criterion for the existence or non-existence of turbulence in the stably stratified environment (Arya, 1999). The Richardson number which is a ratio of buoyancy force to shear stress and the M$O$ stability parameter $\zeta$ (ratio of height $z$, to buoyancy length scale $L$ ) were estimated from the formulations of Arya (1999). The buoyancy length scale $L$ also known as Monin-Obukhov's length is a measure of the depth of the nearsurface layer in which shear effects are likely to be more significant under any stability condition. The empirical relationships used in this study are given as follows

$$
\begin{aligned}
& R_{i}=\frac{g}{T} \frac{\frac{\partial \Theta}{\partial z}}{\left(\frac{\partial u}{\partial z}\right)^{2}} \\
& \zeta=\left\{\begin{array}{cl}
R_{i}, & R_{i}<0 \\
\frac{R_{i}}{1-5 R_{i}}, & 0 \leq R_{i}<0.2
\end{array}\right.
\end{aligned}
$$


Abiye et al.: A Simple Meteorological Preprocessor (SIMETPRO) for Optimizing Hands-On

$\zeta=z / L$

\section{Surface Friction Velocity $\left(u_{*}\right)$}

The magnitude of the surface friction velocity $u_{*}$ which serves as a measure of the vertical transport of horizontal momentum and hence the atmosphere's ability to drift and lift pollutants from the earth's surface was determined from gradient measurement of wind speed. This method was preferred to the usual iterative scheme proposed by Businger et al (1971) because the iterative method was found to always fail under stable conditions especially in a low wind condition (Berkowicz and Prahm, 1982; Stull and Bruce, 2006) typical of the of the present study site. Hence, an alternative method to avoid this disadvantage (Arya, 2001) was adopted as follows

$u_{*}=\frac{k \Delta u}{\phi_{m} \ln \left(z_{2} / z_{1}\right)}$

The M-O dimensionless similarity heat and momentum stability terms $\phi_{\mathrm{h}}$ and $\phi_{\mathrm{m}}$ as a function of geometric mean height of the measurement levels $\left(\mathrm{z}_{\mathrm{m}}\right)$ and Obukhov's length $L$ were determined as follows:

$\phi_{m}=\left\{\begin{array}{rr}(1-15 \zeta)^{-\frac{1}{4}}, & \zeta\left(z_{m} / L\right)<0 \\ 1+15 \zeta, & \zeta\left(z_{m} / L\right)>0\end{array}\right.$
$\phi_{h}=\left\{\begin{array}{rr}(1-15 \zeta)^{-\frac{1}{2}}, & \zeta\left(z_{m} / L\right)<0 \\ 1+15 \zeta, & \zeta\left(z_{m} / L\right)>0\end{array}\right.$

\section{Bowen Ratio $(\beta)$}

The Bowen ratio, $\beta$ (Kakosimos et al., 2011); the ratio of sensible heat flux $(H)$ to latent heat flux $(\lambda \mathrm{E})$, was estimated from the gradient of air temperature $(T)$ and specific humidity $(q)$ as follows:

$\beta=\frac{H}{\lambda E} \cong \gamma \frac{\Delta T}{\Delta q}$

where $\gamma$ is the psychometric constant (0.4 $\left.\mathrm{g} / \mathrm{kg} \cdot \mathrm{K}^{-1}\right) . \Delta T$ and $\Delta q$ are gradients of air temperature and specific humidity, respectively. In order to obtain the specific humidity, an estimate of the saturated vapor pressure (SatVP) and vapor pressure $(V P)$ is required. A polynomial approximation method by Lowe (1977) was adopted.

$$
\begin{aligned}
& \text { SatVP }=0.1\left(A_{0}+A_{1} T+A_{2} T^{2}+A_{3} T^{3}\right. \\
& \left.+A_{4} T^{4}+A_{5} T^{5}+A_{6} T^{6}\right)
\end{aligned}
$$

where

$A_{0}=6.107799961, A_{1}=(4.436518521)^{-01}$,

$A_{2}=(1.428945805)^{-02}, A_{3}=(2.650648471)^{-04}$,

$A_{4}=(3.031240396)^{-06}, A_{5}=(2.034080948)^{-08}$,

$A_{6}=(6.136820929)^{-11}$

The vapor pressure $(\mathrm{KPa})$ was estimated from

$V P=\frac{S a t V P * R H}{100}$

$R H$ is the relative humidity (\%)

\section{Sensible Heat Flux $(H)$}

Simple parameterizations were made from the surface energy balance equation in (12) (Oke, 1978) with $\lambda \mathrm{E}=\mathrm{H} / \beta$ from (9)

$$
R_{N}=H+\lambda E+G
$$

In cases when direct measurements of $R_{N}$ (net radiation) and $G$ (ground heat flux) are available, the above expression for sensible heat flux was represented as

$H=\frac{\left(R_{N}-G\right)}{1+1 / \beta}$

In order to ensure that the estimated sensible heat flux obtained from the method above was bounded within the limits of reasonable values [it is known that the Bowen ratio breaks down in the region $-1.25<\beta<-0.75$ (Ohmura, 1982; Jegede et al., 2001)], an approximation for the sensible heat flux was introduced using tested empirical relationship obtained from measured dataset at the study site. Whenever there is a breakdown, $H_{\text {est }}$ $=a R_{N}$ was used where $\alpha$ is a constant that is location dependent.

\section{Convective Velocity Scale $\left(\omega_{*}\right)$}

The convective velocity scale $\omega_{*}$ of turbulence in the surface layer was estimated following the formulation of Deardorff (1970)

$\omega_{*}=\left(\frac{g}{T} \frac{H}{\rho C_{p}} z_{m d}\right)^{1 / 3}$

However, for the periods when estimates of the 
mixed layer depth $Z_{i c, i m}$ are unrealistic, Wyngaard and Brost (1984) formulation was adopted to calculate the convective velocity scale as in (15).

$\omega_{*}=4.74\left(\frac{H}{\rho C_{p}}\right)^{1 / 2}$

\section{Monin-Obuhkov's Length $(L)$}

With a known estimate of the surface friction velocity $u_{*}$ and sensible heat flux $H_{S}$ in equation (6) and (13) respectively, the Monin-Obukhuv's length for the stable (Venkatram, 1980) and convective (Cimorelli et al., 2004) boundary layer was estimated from equation (16) and (17) respectively.

$L=\frac{T u_{*}^{2}}{k g \theta_{*}}$

$L=-\frac{\rho c_{p} T u_{*}^{3}}{k g H}$

Where, $\rho$ is the density of dry air $\left(\mathrm{kgm}^{-3}\right), c_{p}$ is the specific heat capacity of air $\left(\mathrm{Jkg}^{-1} \mathrm{~K}^{-1}\right), T$ is the ambient temperature $(\mathrm{K})$, and $g$ is the acceleration due to gravity $\left(\mathrm{ms}^{-1}\right)$

Mixed Layer Height, $\mathrm{z}_{\mathrm{i}}$

For unstable conditions (stability classes A, B and
C), equation (18) from Giovannoni (1993) was adopted for estimating the convective mixing height $z_{\mathrm{ic}}$. For stable and neutral conditions, equation (19) from Cimorelli et al (2004) was used to estimate the mechanical mixing height $z_{\text {im }}$. Schematics of the SIMETPRO is presented in Figures 1 and 2 .

$$
\begin{aligned}
& z_{i c}=-k L\left(\frac{\omega_{*}}{u_{*}}\right)^{3} \\
& z_{i m}=2300 u_{*}^{3 / 2}
\end{aligned}
$$

\section{Test validation for $\boldsymbol{H}_{s}$ and $\boldsymbol{u}_{*}$}

To validate the estimates of sensible heat flux $\left(H_{s}\right)$ and friction velocity $\left(\boldsymbol{u}_{*}\right)$ obtained from SIMETPRO, direct measurements were obtained from an independent field experiment carried out at Obafemi Awolowo University Teaching and Research Farm, Ile-Ife between 20 and 21 July, 2014. The measurement site (Figure 3) was a grass covered $20 \times 20 \mathrm{~m}^{2}$ with well-levelled surface. The instrumentation at the site comprised a $6 \mathrm{~m}$ mast and an Eddy-Covariance (EC) measurement system. The EC sytem is the most accurate and straight forward (direct) technique available for 
Abiye et al.: A Simple Meteorological Preprocessor (SIMETPRO) for Optimizing Hands-On

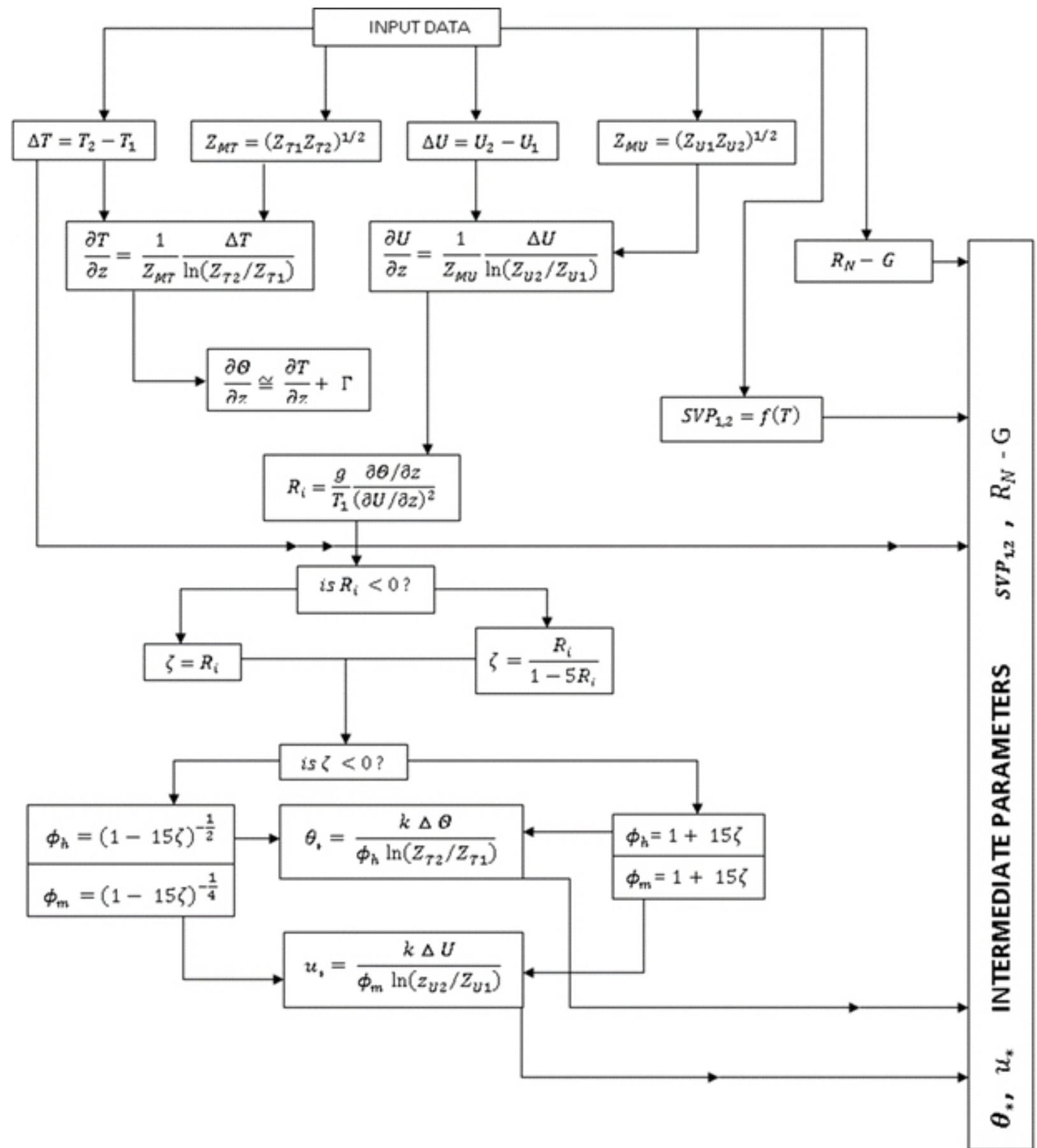

Figure 1: A schematic of the SIMETPRO flow chart 
Abiye et al.: A Simple Meteorological Preprocessor (SIMETPRO) for Optimizing Hands-On

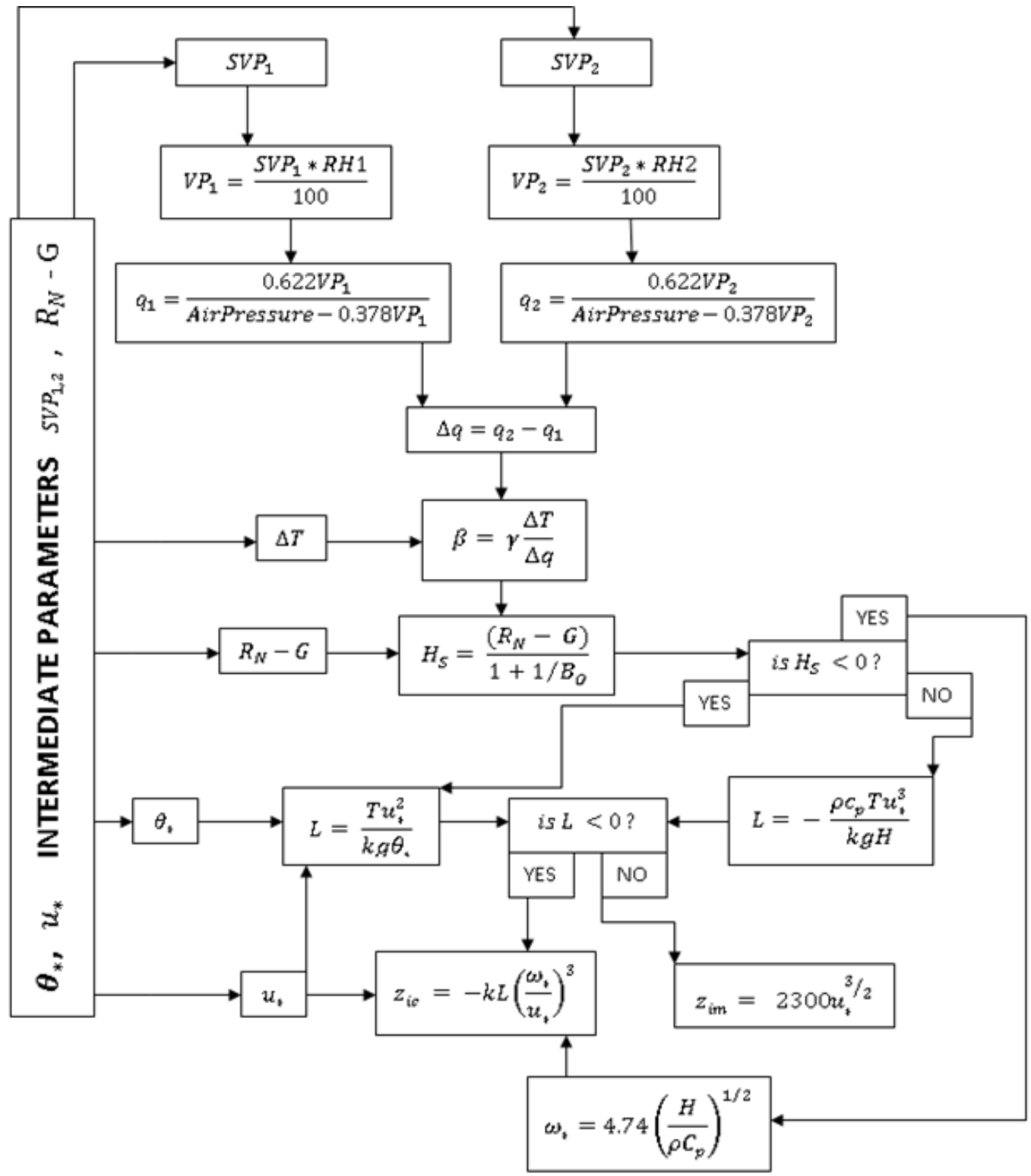

Figure 2: SIMETPRO flow chart (cont'd)

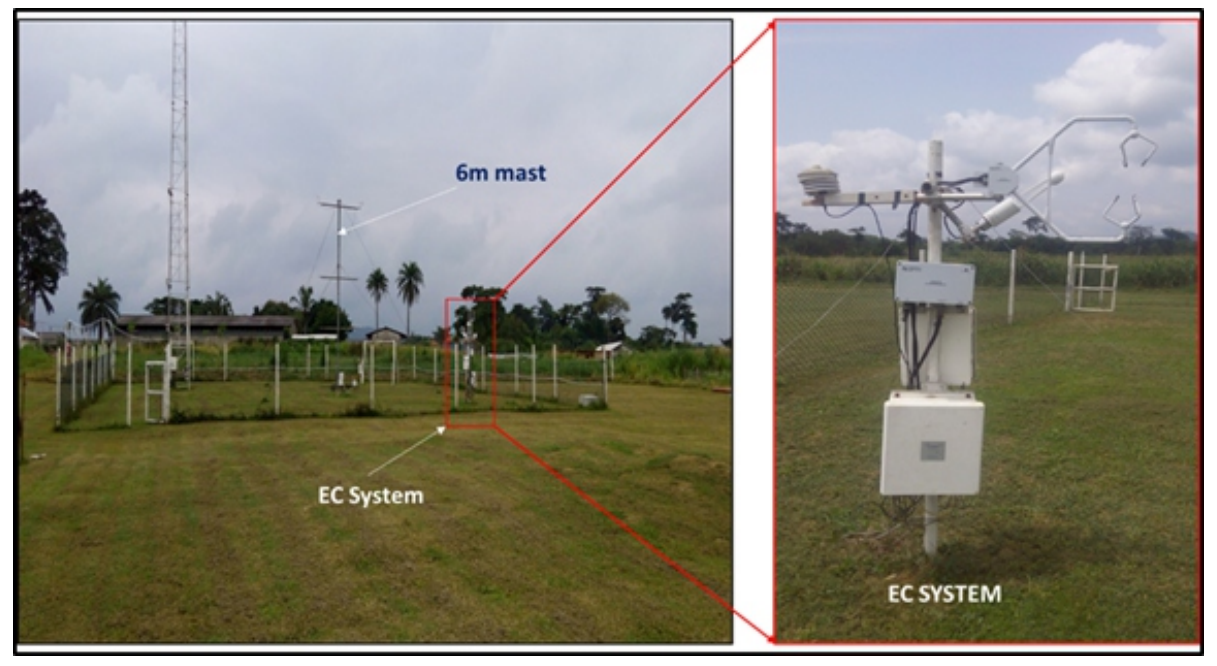

Figure 3: The independent Eddy covariance measurement site at Obafemi Awolowo University Teaching and Research Farm. (station is maintained by the Atmospheric Physics Research Group) 
measuring energy fluxes at the surface (Jegede, 2001). The meteorological mast was designed purposely for profile measurements of wind speed, air temperature and relative humidity at three heights $(0.5 \mathrm{~m}, 2.0 \mathrm{~m}, 5 \mathrm{~m})$ each, net radiaton flux $(1.5 \mathrm{~m})$ and ground heat flux $(5 \mathrm{~cm}$ below surface). The height configurations were so chosen in such a way that the Bowen ratio energy balance (BREB) method adopted in the SIMETPRO can be tested. Thirty minutes averages of measured meteorological variables at the experimental site were used to compute the sensible heat flux from the preprocessor and its values were compared with those measured by the EC system. It was observed that the BREB method mostly breaks down during the early morning period, this is particularly so when the $\beta$ is in the range $-1.25<\beta<-0.75$ and thus the sensible heatflux estimate becomes unrealistic. The criterion to discard all values of $\beta$ in the range $-1.25<\beta<-0.2$ (Ohmura, 1982) were jettisoned in this study. Instead of rejecting data points in this range, a boundary condition was imposed on the BREB method in the interval of the breakdown. The boundary condition employs an empirical constant (an average value of 0.23 ) obtained from probing the ratio of sensible heat flux to the net radiation flux as a rough estimate for $H_{s}$ to minimise the number of data gap in the final analysis. The estimated $H_{s}$ was capped at a maximum value of $250 \mathrm{Wm}^{-2}$ which is typical for a tropical location such as Nigeria, following the results of Jegede (2001).

\section{SIMETPRO Outputs}

Diurnal trend of the test validation for $H_{s}$ and $u_{*}$ are presented in Figure 4. Although the temporal changes in the fluxes were well reproduced by the SIMETPRO, it tends to overestimate the values in both cases. $H_{s}$ was overestimated by a factor of 0.8 - 1.6 and $1.2-4.5$ for $u_{*}$ during the more convective period of 20 July. The day was characterized by intense solar with the net all-wave radiation reaching up to $900 \mathrm{Wm}^{-2}$. Ground heat flux for the same period reached $250 \mathrm{Wm}^{-2}$. With less intense heating of the surface i.e. less convective period, the estimates were much improved. Clearly, this indicates that the stability characterization scheme of the preporocessor needed to be reviewed. Figure 5 presents the diurnal trend (at mean, 25/75 and 5/95th quantiles) for some parameters processed from the SIMETPRO which are required in dispersion models. Mean friction velocity drops below 0.2 $\mathrm{ms}^{-1}$ with instantaneous value up to $0.6 \mathrm{~ms}^{-1} .95^{\text {th }}$ quantile of boundary layer mixing height was 2000 meters driven by an equivalent sensible heat flux of $180 \mathrm{Wm}^{-2}$. Generated potential temperature gradient fully represents the physical dynamics of day-night transition with extreme stability conditions at morning hours, $95^{\text {th }}$ quantile between 0.3 and 0.6. Inter-year comparion of the output is presented in Figure 6. The fluctuations in the estimates could be linked to changes in the underlying atmospheric variables within seasons and also the influence of the pollution plume in the measurement environment. 
Abiye et al.: A Simple Meteorological Preprocessor (SIMETPRO) for Optimizing Hands-On

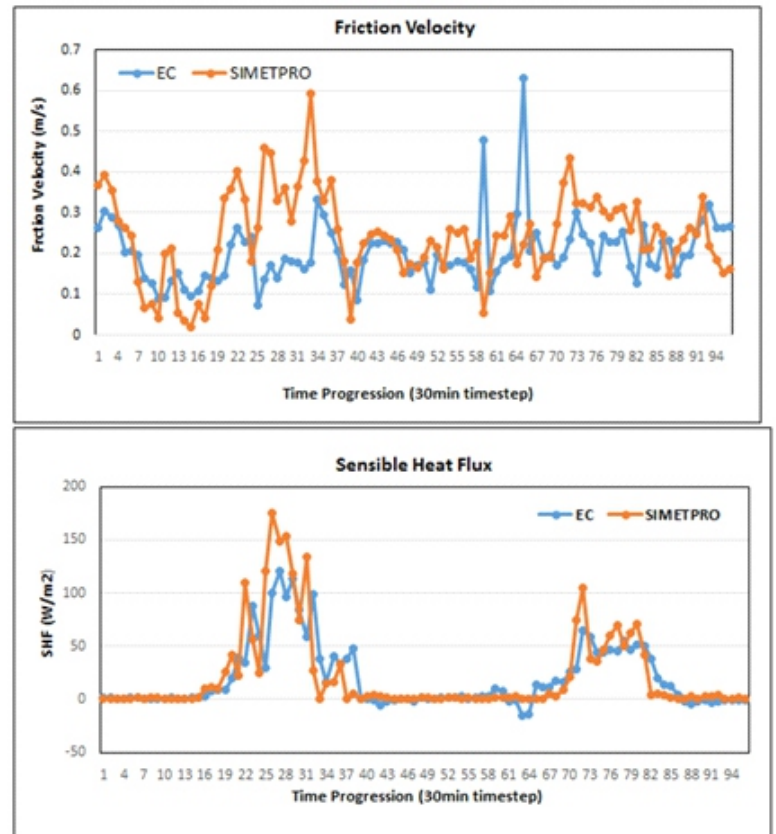

Figure 4: Test validation for $H_{s}$ and $u_{*}$ from EC and SIMETPRO.
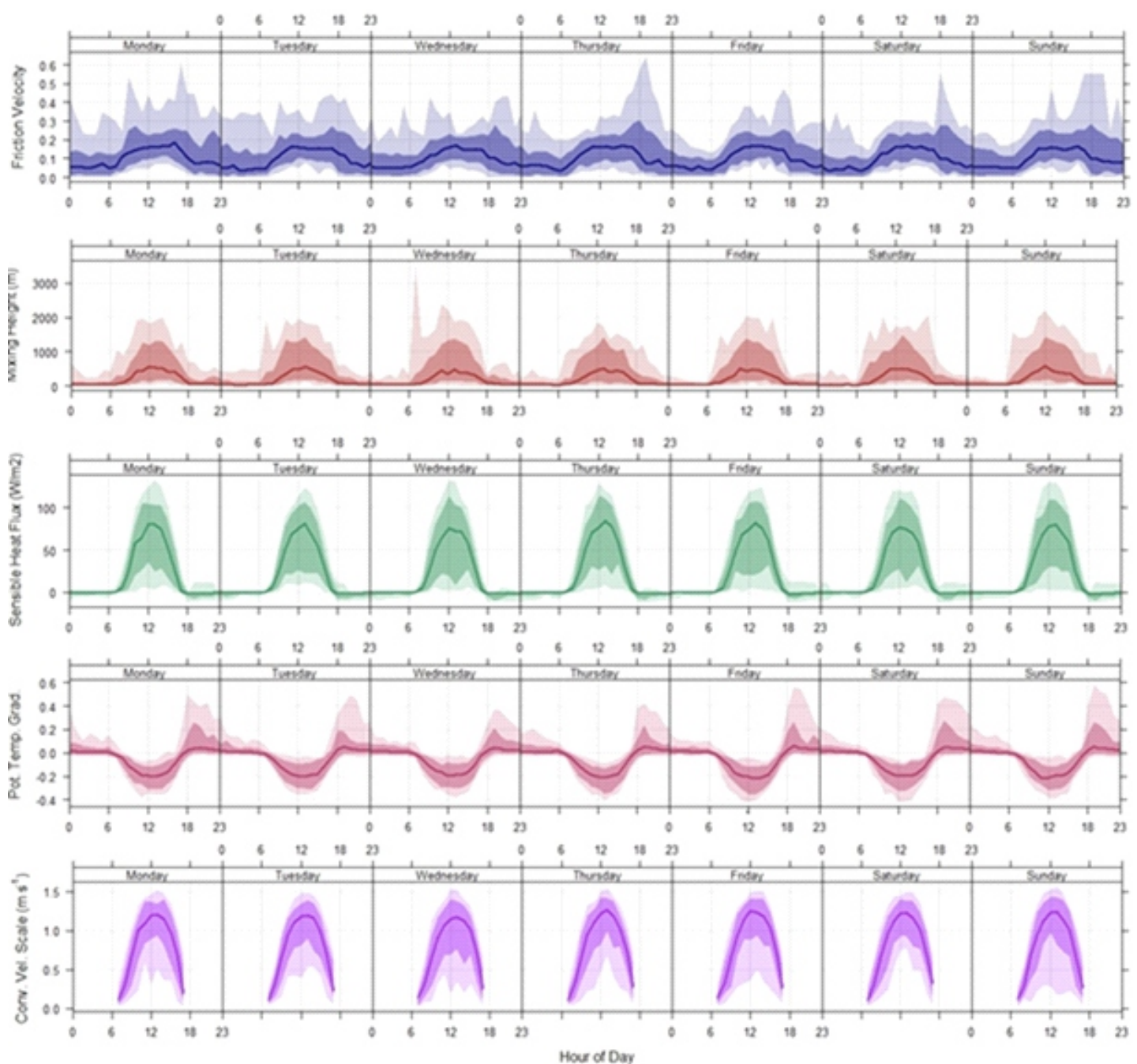

Figure 5: Diurnal trends of SIMETPRO outputs 

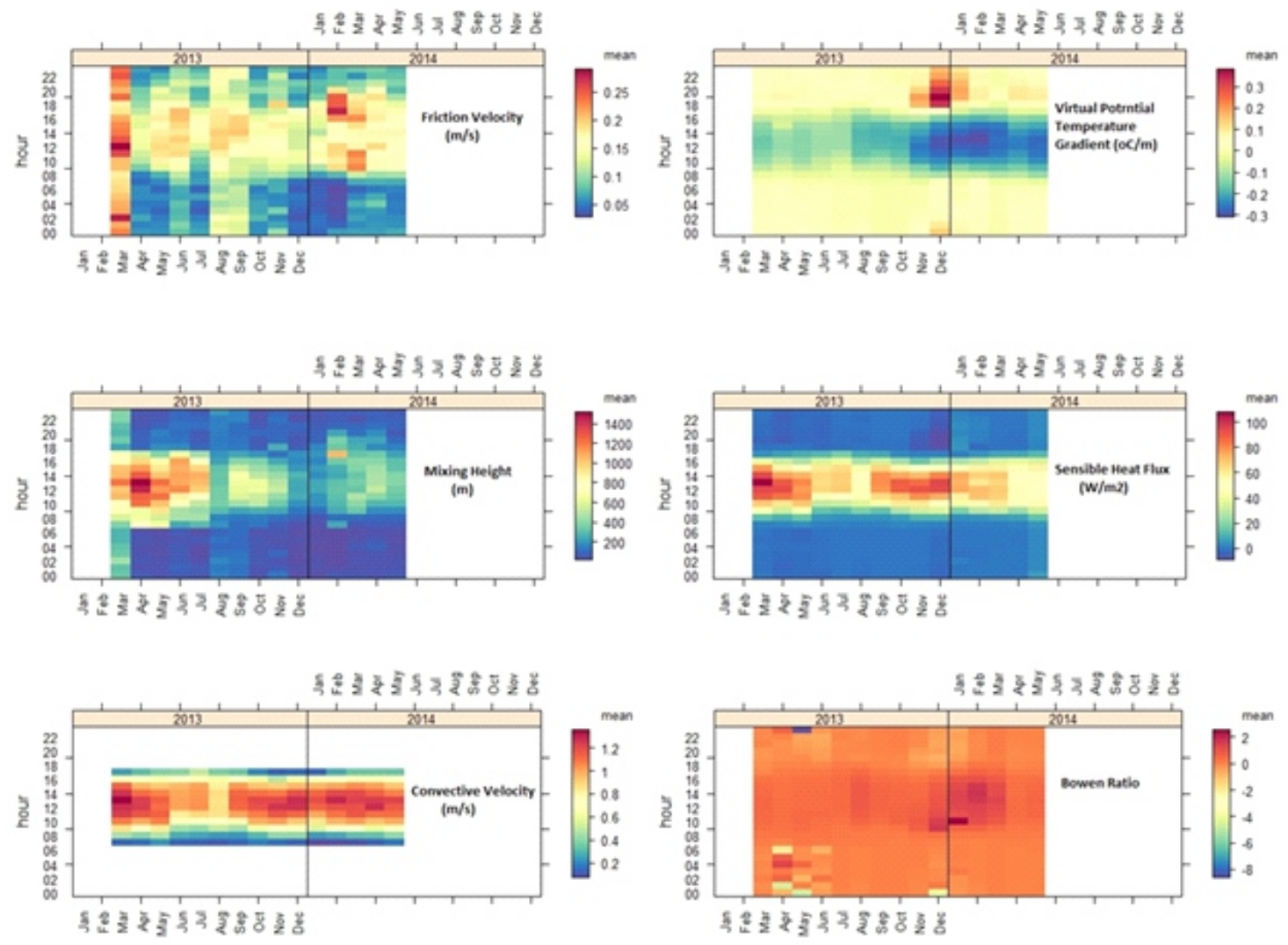

Figure 6: Inter-year comparison of SIMETPRO outputs.

\section{Limitations and Future Improvement}

Of all the deterministic parameters generated from SIMETPRO, this study was only able to validate the estimates of sensible heat flux and friction velocity with direct measurement from Eddy covariance (EC) system. It is important to note that the EC system was setup independently at a location different from the primary study site. Given this condition, certain limitations are obvious and herein enumerated; (1) the difference in terrain and fetch requirement/availability between the location of the EC system and the study site constitute a source of error which may arise due to inhomogeneity in the measured surface parameters used in running the preprocessor (2) albeit the substantial effort, validating only two parameters (sensible heat flux and friction velocity) among many others is rather insufficient and considering also that a scanty twoday dataset was used. Regardless of the fact that procuring, setting-up and maintaining an EC system together with an operational meteorological station is capital and human resource intensive, longer measurement period would be more appropriate (3) the gradients of air temperature and wind speed measurement were taken from a meteorological mast that is less than $10 \mathrm{~m}$ (a minimum requirement stipulated by World Meteorological Organization). As such, the surface wind shear may not have been adequately represented.

In the future when funding and research equipment are available, the SIMETPRO needs to be refined and well-tested. This would require an intensive observation period at an integrated experimental site comprising a tetheredsonde/radiosonde for mixing height profiling, setup of an EC system for measuring surface energy fluxes, radiation sensors, and profile measurement of air temperature, relative humidity and wind speed up to $10 \mathrm{~m}$ and above. While the SIMETPRO is not intended as a replacement for standard preprocessors such as AERMET, it is however important to compare its performance for assessment of uncertainties when used to run dispersion simulation; a core goal for future study. 


\section{ACKNOWLEDGEMENT}

The authors fully acknowledged and appreciate the generous financial support, meteorological sensors and human resources provided by the Atmospheric Physics Research Group (APRG, led by Prof. O.O. Jegede) in the Department of Physics and Engineering Physics, Obafemi Awolowo University, Ile-Ife, Nigeria.

\section{REFERENCES}

Abiye, O. E., Sunmonu, L. A., Ayoola, M. A., Ajao, A. I., Akinola, O. E., Babatunde, O. A. 2017. Near surface meteorological measurements in the vicinity of a scrapiron recycling factory in southwestern Nigeria. FUW Trends in Science and Technology Journal 2:384-390.

Arya, S. P. 2001 . Introduction to Micrometeorology. Academic Press. San Diego, Califonia, USA. 420 pp.

Arya, S. P. 2001 . Introduction to Micrometeorology. Academic Press. San Diego, Califonia, USA. 420 pp.

Arya, S.P. 1999. Air Pollution Meteorology and Dispersion: Oxford University Press, New York. 563 pp

Berkowicz R., Prahm, L. P. 1982. Evaluation of profile method for estimation of surface fluxes of momentum and heat. Atmospheric Environment 12:2809 2819.

Beychok, M. R. 2005. Fundamentals of Stack Gas Dispersion. Irvine, Newport Beach, CA, USA, Fourth Edition. 201 pp.

Businger, J. A., Wyngaard, J. C., Izumi, Y., Bradley, E. F. 1971. Flux-profile relationships in the atmospheric surface layer. Journal of Atmospheric Science 28:181 - 189.

Cimorelli. A. J., Perry, S. G., Venkatram, A., Weil, J. C., Paine, R. J., Wilson, R. B., Lee, R. F., Peters, W. D., Brode, R. W. 2004. AERMOD: A Dispersion Model for Industrial Source Applications. Part I: General Model Formulation and Boundary Layer Characterization" Journal of Applied Meteorology 44:682 693.

Deardoff, J. W. 1970. Convective velocity and temperature scales for the unstable planetary boundary layer and for Rayleigh convection. Journal of Atmospheric Science 27:1211-1213.

Giovannoni, J. M. 1993. Modeling of SO2, Pb and $\mathrm{Cd}$ atmospheric deposition over a one year Period. Atmospheric Environment 27:1793-1808.

Hanna, S. R., Chang J. C. 1993. Hybrid plume dispersion model improvements and testing at three field sites. Atmospheric Environment 27 (9):1491-1508.

Jegede, O. O. 1994a. A meteorological preprocessor for the next generation Gaussian air pollution models usable at low latitudes. Wessex Institute of Technology Air Pollution Conference, 27 -29, September 1994, Barcelona, Spain.

Jegede, O. O. 1994b. On the variation of the mean convective mixed-layer depth over Africa. Meteorologiz Zeitschrift, N.F. 3: $307-311$.

Jegede, O. O., Foken, T., Balogun, A. A., Abimbola, O. J. 2001. Bowen ratio determination of sensible and latent heat fluxes in a humid tropical environment at Ile-Ife, Nigeria, MAUSAM, 52(4): 669678.

Kakosimos, K. E., Assael, M. J., Lioumbas, J. S., Spiridis, A. S. 2011. Atmospheric dispersion modelling of the fugitive particulate matter from overburden dumps with numerical and integral models. Atmospheric Pollution Research 2:24-3.

Karppinem, A., Joffre, S. M., Vanjama, P. 1997. Boundary-layer parameterization for Finnish regulatory dispersion model. International Journal of Environmental Pollution 8(6) 557 - 564.

Lowe, P. R. 1977. An approximating polynomial for computation of saturation vapor pressure. Journal of Applied Meteorology 16:100 - 103.

Ohmura, A. 1982. Objective criteria for rejecting data for Bowen ratio flux calculations. Journal of Applied Meteorology 48:167 _ 178.

Oke, T. R. 1978. Boundary Layer Climates. John Wiley and Sons, New York.

Perry, S. G. 1992. CTDMPLUS: A dispersion model for sources in complex topography. 
Abiye et al.: A Simple Meteorological Preprocessor (SIMETPRO) for Optimizing Hands-On

Part I: Technical formulations. Journal of Applied Meteorology 31:633-645.

Perry, S. G., Cimorelli, A. J., Paine, R. J., Brode, R. W., Weil, J. C., Venkatram, A., Wilson, R. source applications Part II: Model performance against seventeen fieldstudy databases.

Stull, R., Bruce, A. 2006. A simple model for pollution dispersion in a convective boundary layer. Journal of Applied
Meteorology 45:1127-1743.

Venkatram, A. 1980. Estimating the MoninObukhov length in the stable boundary layer for dispersion calculations. Boundary Layer Meteorology 19:481 485.

Wyngaard, J. C., Brost, R. A. 1984. Top-down and bottom-up of a scalar in the convective boundary layer. Journal of Atmospheric Science 41:102-112. 